\title{
Hippocampal sclerosis in paracoccidioidomycosis
}

\author{
Esclerose hipocampal na paracoccidioidomicose \\ Marcos ROSA-JÚNIOR', Mariana Lacerda Reis GRENFELL², Paulo Mendes PECANHA ${ }^{3}$
}

A 39-year-old man presented with complex partial seizures five years after treatment of central nervous system (CNS) paracoccidioidomycosis (PCM). Post-treatment images showed reduction of the CNS lesions and appearance of hippocampal sclerosis (HS) (Figures 1 and 2). To the best of our knowledge, this is the first description between PCM and HS.

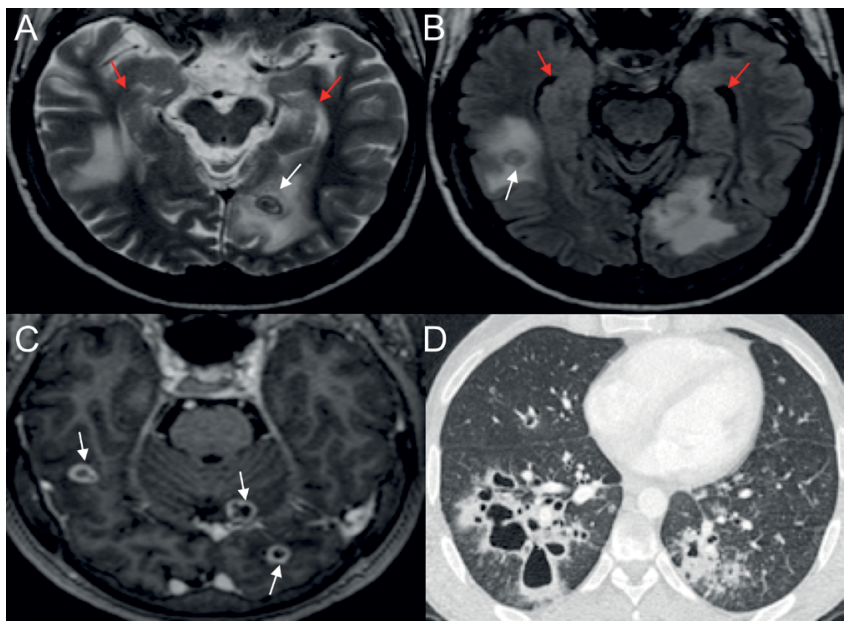

Figure 1. (A) and (B) - T2WI and FLAIR show lesions with low T2WI signal (white arrows) with vasogenic edema. Note the normal hippocampi (red arrows). (C) - T1 post-contrast shows lesions with annular enhancement (white arrows). (D) - chest CT with cavitated lesions.
HS is a common pathological finding in temporal lobe epilepsy ${ }^{1}$. The etiology is controversial, whether acquired or developmental, however triggering factors of HS can be epilepticus status, febrile seizures, infectious and vascular diseases or malformations. When associated with other diseases, as in this case of $\mathrm{PCM}^{2,3}$, it is called dual pathology.

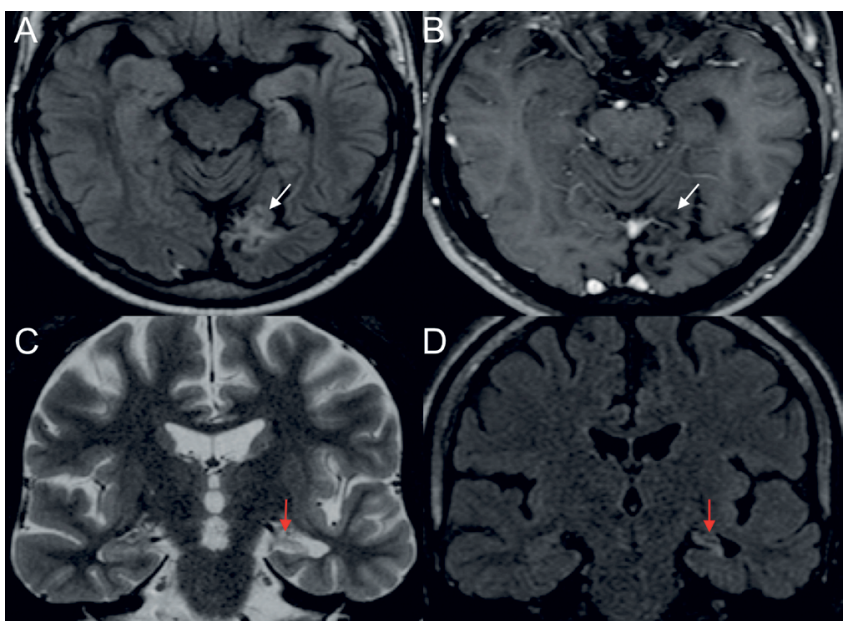

Figure 2. (A) (FLAIR) and (B) (T1 post-contrast) - show lesion resolution and encephalomalacia after treatment (white arrows). (C) and (D) T2 and FLAIR - show volumetric reduction, signal hyperintensity and loss of internal architecture of the left hippocampus (red arrows) - HS.
1. Liu Z, Mikati M, Holmes GL. Mesial temporal sclerosis: pathogenesis and significance. Pediatr Neurol. 1995 Jan;12(1):5-16. https://doi. org/10.1016/0887-8994(94)00122-i

2. Rosa Júnior M, Baldon IV, Amorim AC, Melo AFC Peçanha P, Falqueto A, et al. Imaging paracoccidioidomycosis: A pictorial review from head to toe. Eur J Radiol. 2018 Jun;103:147-62. https://doi. org/10.1016/j.ejrad.2018.03.026

3. Rosa Júnior M, Amorim AC, Baldon IV, Martins RM, Pereira RP, Campos SS, et al. Paracoccidioidomycosis of the Central Nervous System: CT and MR imaging findings. AJNR Am J Neuroradiol. 2019 Oct;40(10):1681-8. https://doi.org/10.3174/ajnr.A6203

\footnotetext{
${ }^{1}$ Universidade Federal do Espírito Santo, Hospital Universitário Cassiano Antônio de Moraes, Departamento de Neurorradiologia, Vitória ES, Brazil. ${ }^{2}$ Universidade Federal do Espírito Santo, Hospital Universitário Cassiano Antônio de Moraes, Departamento de Neurologia, Vitória ES, Brazil. 3Universidade Federal do Espírito Santo, Hospital Universitário Cassiano Antônio de Moraes, Departamento de Doenças Infecciosas, Vitória ES, Brazil. Marcos ROSA JÚNIOR (iD) https://orcid.org/0000-0001-8668-2804; Paulo Mendes PEC̦ANHA (iD) https://orcid.org/0000-0003-1387-5554

Correspondence: Marcos Rosa-Júnior; Departamento de Neurorradiologia, HUCAM/UFES/EBSERH; Av Marechal Campos, 1355 ; $29043-260$ Vitória ES, Brazil; E-mail:marcos.rosa@ufes.br

Conflict of interest: There is no conflict of interest to declare.

Received on November 28, 2019; Received in its final form on January 8, 2020; Accepted on January 27, 2020.
} 